\title{
Time Series Analysis on Selected Rainfall Stations Data in Louisiana Using ARIMA Approach
}

\author{
Yaw A. Twumasi ${ }^{*}$, Jacob B. Annan1, Edmund C. Merem² ${ }^{2}$ John B. Namwamba1, \\ Tomas Ayala-Silva ${ }^{3}$, Zhu H. Ning1, Abena B. Asare-Ansah', Judith Oppong1, \\ Diana B. Frimpong1, Priscilla M. Loh ${ }^{1}$, Faustina Owusu ${ }^{1}$, Lucinda A. Kangwana ${ }^{1}$, \\ Olipa S. Mwakimi ${ }^{4}$, Brilliant M. Petja ${ }^{5}$, Ronald Okwemba1, Caroline O. Akinrinwoye ${ }^{1}$, \\ Hermeshia J. Mosby ${ }^{1}$, Joyce McClendon-Peralta ${ }^{1}$

\begin{abstract}
${ }^{1}$ Department of Urban Forestry and Natural Resources, Southern University and A\&M College, Baton Rouge, Louisiana, USA
${ }^{2}$ Department of Urban and Regional Planning, Jackson State University, Jackson, Mississippi, USA

${ }^{3}$ USDA-ARS Tropical Agriculture Research Station, Mayaguez, Puerto Rico, USA

${ }^{4}$ Institute of Resource Assessment, University of Dares Salam, Dares Salam, Tanzania

${ }^{5}$ Water Research Commission (WRC) Private Bag X03, Gezina, South Africa

Email: ^yaw_twumasi@subr.edu, *yaw.twumasi@gmail.com
\end{abstract}

How to cite this paper: Twumasi, Y.A., Annan, J.B., Merem, E.C., Namwamba, J.B., Ayala-Silva, T., Ning, Z.H., Asare-Ansah, A.B., Oppong, J., Frimpong, D.B., Loh, P.M., Owusu, F., Kangwana, L.A., Mwakimi, O.S., Petja, B.M., Okwemba, R., Akinrinwoye, C.O., Mosby, H.J. and McClendon-Peralta, J. (2021) Time Series Analysis on Selected Rainfall Stations Data in Louisiana Using ARIMA Approach. Open Journal of Statistics, 11, 655-672.

https://doi.org/10.4236/ojs.2021.115039

Received: June 13, 2021

Accepted: September 27, 2021

Published: September 30, 2021

Copyright $\odot 2021$ by author(s) and Scientific Research Publishing Inc. This work is licensed under the Creative Commons Attribution International License (CC BY 4.0).

http://creativecommons.org/licenses/by/4.0/

(c) (i) Open Access

\begin{abstract}
Precipitation is very important for both the environment and its inhabitants. Agricultural activities mostly depend on precipitation and its availability. Therefore, the ability to predict future precipitation values at specific stations is key for environmental and agricultural decision making. This research developed Autoregressive Integrated Moving Average (ARIMA) models for selected stations with Integrated component and Autoregressive Moving Average (ARMA) for selected stations without Integrated component at Louisiana State. The ARIMA module is represented as ARIMA(p, d, q)(P,D,Q). The selected lag order for the Autoregressive (AR) component is represented with $\mathrm{p}$ and $\mathrm{P}$ for seasonal AR component, while the integrated form (number of times data were differenced) is $\mathrm{d}$ and $\mathrm{D}$ for seasonal differencing, and the Moving Average (MA) lag order is $\mathrm{q}$ and $\mathrm{Q}$ for seasonal MA component. Data from 1950 to 2020 were employed in this research. Results of the analysis indicated that Baton Rouge (ARIMA $\left.(0,1,1)(0,0,2)_{12}\right)$, Abbeville (ARMA $\left.(0,0,1)(0,0,2)_{12}\right)$, Monroe Regional (ARMA $\left.(0,0,1)(0,0,0)_{12}\right)$, New Orleans Airport (ARMA $\left.(1,0,0)(0,0,2)_{12}\right)$, Alexandria (ARMA $\left.(1,0,1)(0,0,0)_{12}\right)$, Logansport (ARIMA $\left.(0,1,2)(0,0,0)_{12}\right)$, New Orleans Audubon (ARMA $(1,0,0)$ $\left.(0,0,0)_{12}\right)$, Lake Charles Airport (ARMA $\left.(2,0,2)(0,0,0)_{12}\right)$ are the best ARIMA models for predicting precipitation in Louisiana. The models were used to predict the average monthly rainfall at each station. The highest precipitation
\end{abstract}


observed in Louisiana was recorded in 1991. The Precipitation in Louisiana fluctuated over the years but has adopted a decreasing trend from the year 2000 to 2020 . It was recommended that the government, researchers, and individuals take note of these models to make future plans to help increase the production of agricultural commodities and prevent destructions caused by excessive precipitation.

\section{Keywords}

Precipitation, ARIMA Models, Time Series, Lowess, Louisiana

\section{Introduction}

Precipitation is a key meteorological variable used by scientist in the studies of the influence of climate change on water reserves [1] [2] [3]. [4] also clarifies the fact that precipitation is one of the main variables used in hydrological modelling for predicting availability of water at various water bodies. In studying precipitation, measurement of precipitation taken at ground level is considered the best values [5]; thus the values used in this study were measured from ground level from gauging stations.

Agricultural or forestry activities are mostly planned with regards to availability of rainfall [6]. Nonetheless, not only agricultural or forestry activities need information on precipitation to make informed decision but sectors such as climate change, water management and even daily human activities [7].

It has been established by many studies that climate change has had a great impact on all living ecosystems [8] [9] [10] [11] [12]. There has been a noticeable upsurge in precipitation trend in some parts of Europe, America and the central part of Asia [13]; yet some parts of the world precisely the south of Asia and Africa are also experiencing a decline in precipitation [14]. The changes in precipitation can also be attributed to the impact climate change has on all activities [15]. This change in precipitation leads to destructions such as flood and hurricane including other challenges which in extreme terms destroy properties and claim human lives [9]. This makes obtaining foreknowledge about precipitation very key for environmental, agricultural, and all human activities.

Frequency analysis can be employed when studying the behavior of rainfall over a longer period [16] [17] [18] [19] but the results from such studies discuss only extreme values. Nonetheless, different methods have been employed by different researchers to study precipitation and its behavior around the world [20] [21] [22]. Data availability is another issue that is being faced by researchers in the field of natural resources. Obtaining historical data to examine is difficult in most countries. Therefore, reaching accurate conclusion on seasonal or decade trend becomes a real challenge for researchers.

In recent times, changes in precipitation and identification of its extreme values have gained more attention from researchers [21] [22]. Nevertheless, less at- 
tention has been given to time series models and their capability to identify trends and predict future values in terms of precipitation. [23] conducted research on the rainfall in Louisiana using log-Pearson Type 3 (LPEAR3) distribution and created maximum annual rainfall maps. [24] also studied Louisiana rainfall using Multi-satellite Precipitation Analysis (TMPA) and detected rainfall occurrence in real-time. Despite these researchers using Louisiana rainfall data none has considered using powerful time series methods to predict rainfall in Louisiana.

The ability to identify precipitation trends and predicting future precipitation values are very important for both industrial and individual purposes. Therefore, this research seeks to fill the gap in existing literature and contribute towards using Autoregressive Integrated Moving Average (ARIMA) models in modelling individual rain stations in Louisiana. This study investigates from the monthly perspective, precipitation characteristics and trends and construct suitable models to forecast precipitation from data obtain from the interval 1970-2020 from ten stations within Louisiana State in the United States of America.

\section{Data and Methodology}

\subsection{Data}

The data for 10 stations in Louisiana State over the range of 70 years (1950-2020) were obtained from the National Oceanic and Atmospheric Administration (NOAA); National Centers for Environmental Information online dataset discovery (NOAA, 2020). Two stations (Buras in Plaquimines and Chauvin) had more than $50 \%$ of data missing, therefore were omitted from this study. Few imputations were carried out to fill in 5\% missing data in Abbeville and Lake Charles International Airport. This missing data was resolved through mean imputation as described by [25]. The study was based on eight stations shown on Table 1 together with their longitude and latitude.

The stations and their respective locations at Louisiana are shown in Figure 1 below.

Table 1. Stations and locations.

\begin{tabular}{ccc}
\hline Station & Latitude & Longitude \\
\hline Baton Rouge Metro Airport, La Us & 30.5372 & -91.1469 \\
Abbeville, La Us & 29.9688 & -92.1169 \\
Monroe Regional Airport, La Us & 32.5155 & -92.0405 \\
New Orleans Airport, La Us & 30.03333 & -90.0333 \\
Alexandria, La Us & 31.3205 & -92.4611 \\
Logansport, La Us & 31.9672 & -94.0002 \\
Lake Charles Regional Airport, La Us & 30.12472 & -93.2283 \\
New Orleans Audubon, La Us & 29.9166 & -90.1302 \\
\hline
\end{tabular}




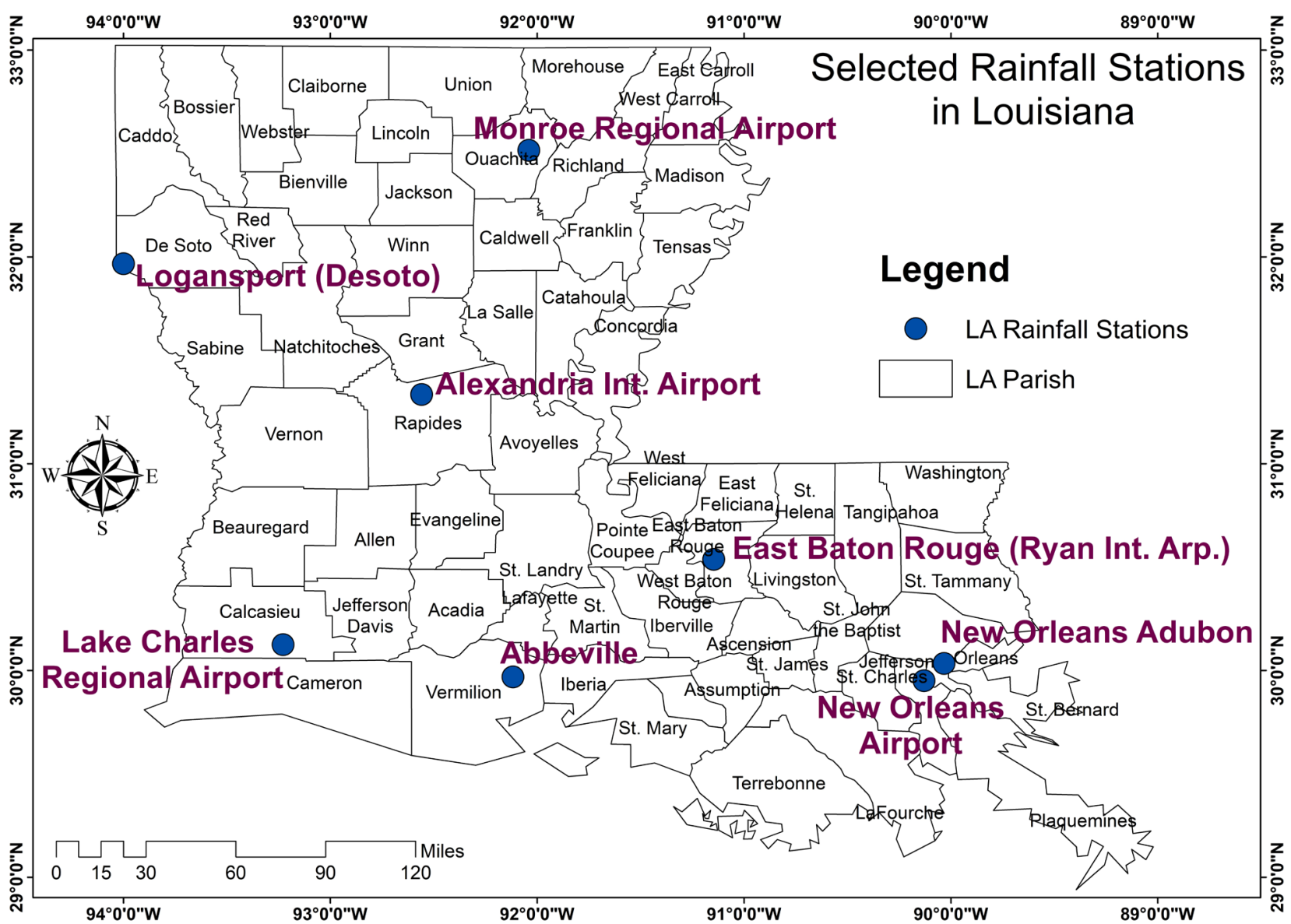

Figure 1. Map of Louisiana state with selected rainfall stations.

\subsection{Statistical Methods}

The data were divided into two parts, the training data (1950-2017) for constructing the model and the test data (2018-2020), this practice was adopted in order to test the best models constructed and measure accuracy of predicted values.

Lowess smooth curve was employed to analyze the long-term trend of all the stations. In order to perform a time series analysis, the stationarity of the data should be determined, and in this study, the Augmented Dickey-Fuller test (ADF) and Kwiatkowski-Phillips-Schmidt-Shin (KPSS) were employed. If the data is not stationary then it must be transformed in order to obtain stationarity in both mean and variance. After obtaining stationarity, Autocorrelation Functions (ACF) and Partial Autocorrelation Functions (PACF) are constructed to obtain the best lag for constructing the model with help of Akaike Information Criterion (AIC) and Bayesian Information Criterion (BIC).

An Autoregressive Integrated Moving Average (ARIMA) model was used in this research. ARIMA model is described by two modules Autoregression (AR) and Moving average (MA) and sometimes an integrated module when the data are not stationary but differenced to achieve stationarity.

The Autoregression (AR) is the module which assumes that the recent value is 
the immediate previous plus random white noise.

$$
y_{t}=\varepsilon_{t}+\phi y_{t-1}
$$

$y_{t}=$ time event under discussion at time $t$

$\varepsilon_{t}=$ immediate random white noise

$y_{t-1}=$ time event under discussion at time $t$

$\phi=$ coefficient of $y_{t-1}$

Moving average (MA) modules assumes that an immediate value is the previous value plus some white noise.

$$
y_{t}=\varepsilon_{t}+\theta \varepsilon_{t-1}
$$

$y_{t}=$ time event under discussion

$\varepsilon_{t}=$ immediate random white noise

$\varepsilon_{t-1}=$ one lagged random white noise

$\theta=$ coefficient of $\varepsilon_{t-1}$

The combination of the AR and MA modules results in Autoregressive Moving Average (ARMA)

$$
y_{t}=\phi_{1} y_{t-1}+\cdots+\phi_{p} y_{t-p}+\varepsilon_{t}+\theta_{1} \varepsilon_{t-1}+\cdots+\theta_{q} \varepsilon_{t-q}
$$

The ARIMA module is represented as $\operatorname{ARIMA}(p, d, q)(P, D, Q)$. The lag order AR component is represented with $p$ and $P$ for seasonal AR component, the integrated form that is number of times data were differenced is $d$ and $D$ for seasonal differencing, and the MA lag order is $q$ and $Q$ for seasonal MA component.

The Box-Jenkins method [26] was employed to build the ARIMA models in this research. This method follows these steps; Identification, Estimation, Diagnostics, and Forecasting. The accuracy of the selected model is then measured using Root Mena Square Error (RMSE) and Mean Absolute Error (MAE).

\section{Results and Discussion}

\subsection{Preliminary Analysis}

Table 2 shows the significant differences in precipitation within the cities in Louisiana State. Over the range of 70 years Baton Rouge recorded the highest monthly precipitation of 30.96. The table also indicates that, there were different months where all stations did not experience any form of precipitation at all. The mean values of precipitation over the years under study are also recorded in Table 2. The standard deviation indicates that the precipitation values are not too far from their mean whiles the skewness indicates that the data for each station is slightly skewed positively but do not have great impact on the normality of the data since the data are slightly huge.

\subsection{Time Series Analysis}

The time series plot represented in Figure 2 shows the pattern of precipitation in all the stations are similar, indicating that high and low altitude of precipitation turn to have the same trend over the years. The Lowess curve on the time 

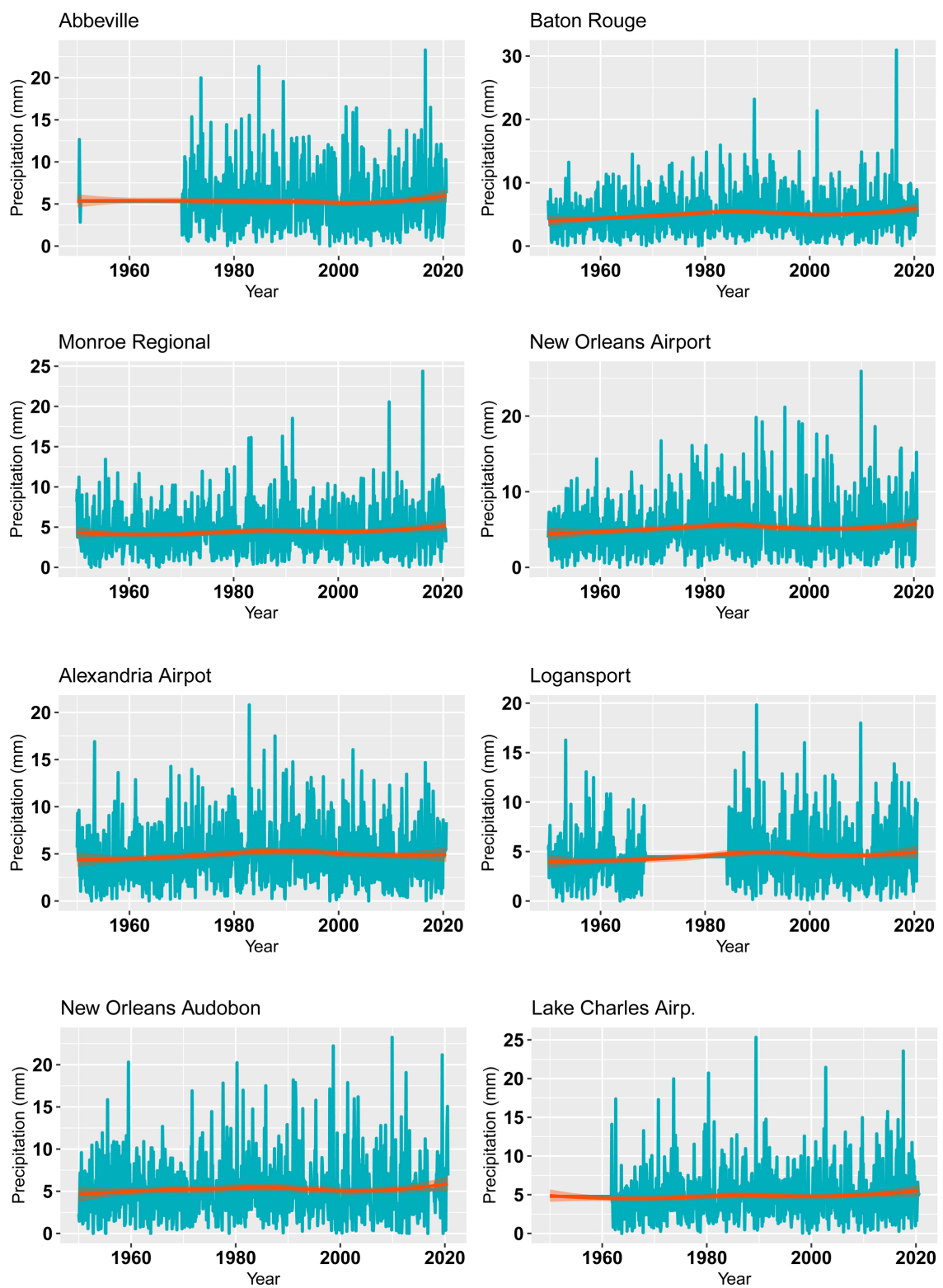

Figure 2. Time series plot of precipitation.

Table 2. Descriptive statistics of precipitation in Louisiana state.

\begin{tabular}{cccccc}
\hline Station & Min & Max & Mean & StDev & Skewness \\
\hline Baton Rouge & 0.000 & 30.960 & 4.956 & 3.266 & 1.63 \\
Abbeville & 0.000 & 23.300 & 5.329 & 3.041 & 1.45 \\
Monroe Regional & 0.000 & 24.370 & 4.393 & 2.963 & 1.40 \\
New Orleans Airport & 0.000 & 25.930 & 5.130 & 3.545 & 1.42 \\
Alexandria & 0.000 & 20.800 & 4.851 & 3.067 & 1.07 \\
Logansport & 0.000 & 19.820 & 4.468 & 2.660 & 1.33 \\
New Orleans Audubon & 0.000 & 23.250 & 5.192 & 3.573 & 1.44 \\
Lake Charles Airport & 0.000 & 25.330 & 4.789 & 3.089 & 1.91 \\
\hline
\end{tabular}


series graph of Baton Rouge indicates precipitation has been fluctuating over time but has adopted an increasing trend in the last decade under study. The precipitation at Abbeville tends to increase and then decrease but keeps a linear trend in the last decade except for some few extreme precipitation values. The time series plot of precipitation for Monroe Regional over the years also shows that precipitation adopted an increasing trend until the 1990s when it dropped but surges again from 2010. Again Figure 2 shows a gradual decrease in the precipitation trend for New Orleans Airport, New Orleans Audubon, Logansport at Desoto, Alexandria International Airport, and Lake Charles International Airport but it is also discovered that all these stations display a steady trend in precipitation but Logansport at Desoto had a fluctuating characteristic from 1990 to 2010 until it obtained its steadiness for the years after.

\subsection{Data Stationarity}

In order to obtain the best fit model for the data, stationarity for the data must be obtained. Augmented Dickey-Fuller (ADF) test and Kwiatkowski-PhillipsSchmidt-Shin (KPSS) test were used to check for the stationarity of the data and the results displayed below.

Table 3 gives information about stationarity of the training data. The ADF test shows that all data are stationary in their original state. The KPSS test also indicates same except for Baton Rouge and Logansport which failed the KPSS test. In order to avoid any doubt, the Baton Rouge and Logansport data were transformed through differencing and they became stationary at first difference. This means the data has qualified for the assumption of stationarity and can be used to construct a suitable model.

\subsection{Model Identification and Selection}

ACF plot helps identify the moving average (MA) component of the model whiles PACF plot identify the auto regressive (AR) component of the model for the data.

Table 3. Stationarity test.

\begin{tabular}{ccccc}
\hline \multirow{2}{*}{ Area } & \multicolumn{2}{c}{ ADF Test } & \multicolumn{2}{c}{ KPSS Test } \\
\cline { 2 - 5 } & $\begin{array}{c}\text { Test } \\
\text { Statistic }\end{array}$ & $\begin{array}{c}\text { Critical Value } \\
(5 \%)\end{array}$ & $\begin{array}{c}\text { Test } \\
\text { Statistic }\end{array}$ & $\begin{array}{c}\text { Critical Value } \\
(5 \%)\end{array}$ \\
\hline Baton Rouge & -7.3595 & -1.95 & 0.8592 & 0.463 \\
Abbeville & -6.2553 & -1.95 & 0.1311 & 0.463 \\
Monroe Regional & -7.5205 & -1.95 & 0.2288 & 0.463 \\
New Orleans Airport & -7.2118 & -1.95 & 0.2980 & 0.463 \\
Alexandria & -7.2492 & -1.95 & 0.3071 & 0.463 \\
Logansport & -6.5043 & -1.95 & 0.4758 & 0.463 \\
New Orleans Audubon & -7.149 & -1.95 & 0.0769 & 0.146 \\
Lake Charles Airport & -6.7857 & -1.95 & 0.0408 & 0.146 \\
\hline
\end{tabular}


Figures 3-6 give detailed information on ACF and PACF of all stations. These graphs would lead to the identification of tentative ARIMA models for each station. The ACF plot for Baton Rouge and Logansport from Figure 5 and Figure 6 respectively, show a cut off after lag 1 while the lags from the PACFs fade gradually, but the spike at lag 12 indicates the presence of seasonality in the data of Baton Rouge and Logansport.

The ACF and PACF lags for Abbeville, Monroe Regional, New Orleans Airport, Alexandria, New Orleans Audubon and Lake Charles Airport cut off sharply after lag one but PACF plots for Abbeville and New Orleans Audubon show a significant spike at lag 12 which suggests the presence of seasonality in dataset for Abbeville and New Orleans Audubon.

Table 4 gives the tentative models for each station obtained from Figures 3-6. Amongst the many possible models, the models with the smallest information criteria are presented. The model with the least AIC and BIC values are then selected as the best.

Table 4. Tentative ARIMA models.

\begin{tabular}{|c|c|c|c|}
\hline Area & Tentative Model & AIC & BIC \\
\hline & $\operatorname{ARIMA}(0,1,1)(1,0,0)_{12}$ & 4206.626 & 4216.008 \\
\hline \multirow[t]{3}{*}{ Baton Rouge } & $\operatorname{ARIMA}(1,1,1)(1,0,0)_{12}$ & 4208.385 & 4222.458 \\
\hline & $\operatorname{ARIMA}(1,1,2)(1,0,1)_{12}$ & 4209.192 & 4227.956 \\
\hline & $\operatorname{ARMA}(1,0,0)(0,0,2)_{12}$ & 4047.963 & 4062.039 \\
\hline \multirow[t]{3}{*}{ Abbeville } & $\operatorname{ARMA}(1,0,1)(0,0,2)_{12}$ & 4049.748 & 4068.517 \\
\hline & $\operatorname{ARMA}(0,0,1)(0,0,2)_{12}$ & 4047.75 & 4061.826 \\
\hline & $\operatorname{ARMA}(0,0,1)(0,0,0)_{12}$ & 4025.361 & 4039.437 \\
\hline \multirow[t]{3}{*}{ Monroe Regional } & $\operatorname{ARMA}(1,0,1)(0,0,0)_{12}$ & 4027.363 & 4046.131 \\
\hline & $\operatorname{ARMA}(1,0,0)(0,0,0)_{12}$ & 4025.558 & 4039.635 \\
\hline & $\operatorname{ARMA}(0,0,1)(0,0,2)_{12}$ & 4314.213 & 4328.289 \\
\hline \multirow[t]{3}{*}{ New Orleans Airport, } & $\operatorname{ARMA}(1,0,1)(0,0,2)_{12}$ & 4315.18 & 4333.948 \\
\hline & $\operatorname{ARMA}(1,0,0)(0,0,2)_{12}$ & 4313.685 & 4327.761 \\
\hline & $\operatorname{ARMA}(0,0,1)(0,0,0)_{12}$ & 4098.667 & 4112.743 \\
\hline \multirow[t]{3}{*}{ Alexandria } & $\operatorname{ARMA}(1,0,1)(0,0,0)_{12}$ & 4095.968 & 4114.737 \\
\hline & $\operatorname{ARMA}(1,0,0)(0,0,0)_{12}$ & 4098.95 & 4113.026 \\
\hline & $\operatorname{ARIMA}(1,1,1)(0,0,0)_{12}$ & 3845.953 & 3859.975 \\
\hline \multirow[t]{3}{*}{ Logansport } & $\operatorname{ARIMA}(0,1,1)(0,0,0)_{12}$ & 3846.859 & 3856.24 \\
\hline & ARIMA $(0,1,2)(0,0,0)_{12}$ & 3845.943 & 3860.016 \\
\hline & ARMA $(0,0,1)(0,0,0)_{12}$ & 4333.322 & 4347.398 \\
\hline \multirow[t]{3}{*}{ New Orleans Audubon } & ARMA $(1,0,1)(0,0,0)_{12}$ & 4333.761 & 4352.529 \\
\hline & $\operatorname{ARMA}(1,0,0)(0,0,0)_{12}$ & 4332.68 & 4346.756 \\
\hline & $\operatorname{ARMA}(1,0,2)(0,0,0)_{12}$ & 4075.573 & 4099.033 \\
\hline \multirow[t]{2}{*}{ Lake Charles Airport } & $\operatorname{ARMA}(2,0,1)(0,0,0)_{12}$ & 4075.827 & 4099.287 \\
\hline & $\operatorname{ARMA}(2,0,2)(0,0,0)_{12}$ & 4072.522 & 4100.674 \\
\hline
\end{tabular}




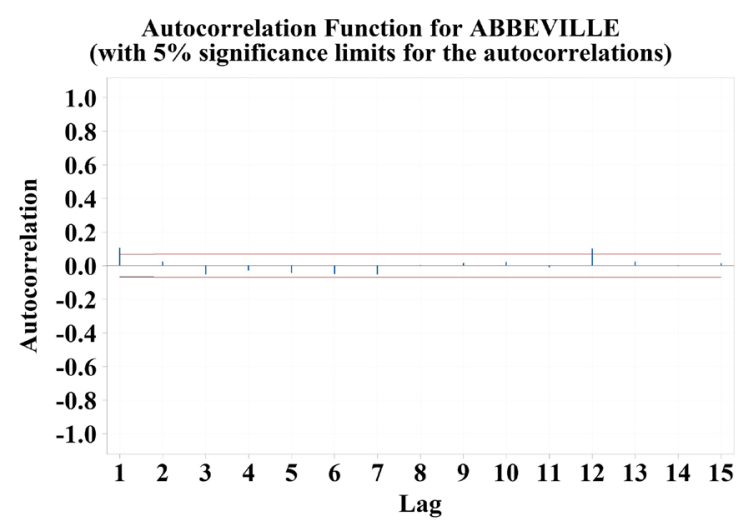

Partial Autocorrelation Function for ABBEVILLE (with 5\% significance limits for the partial autocorrelations)

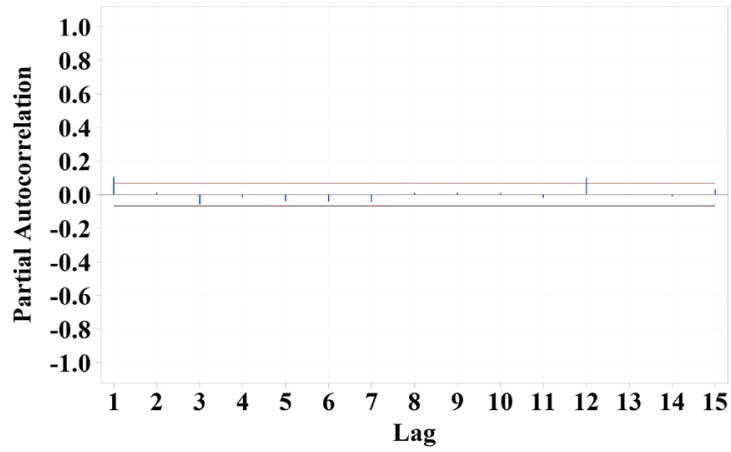

Autocorrelation Function for MONROE REGIONAL (with $5 \%$ significance limits for the autocorrelations)

Partial Autocorrelation Function for MONROE REGIONAL (with 5\% significance limits for the partial autocorrelations)
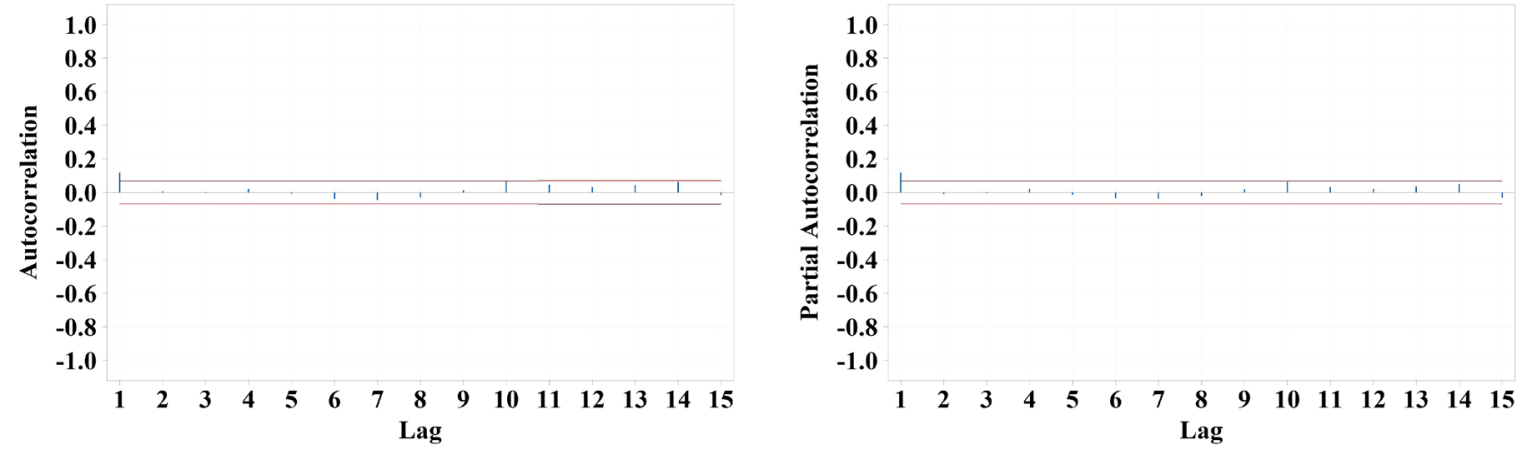

Figure 3. ACF and PACF plots for Abbeville and Monroe regional airport.

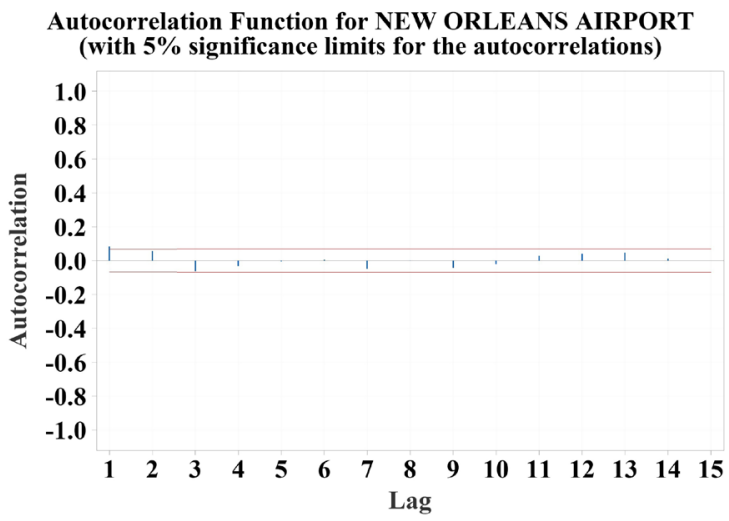

Partial Autocorrelation Function for NEW ORLEANS AIRPORT (with 5\% significance limits for the partial autocorrelations)

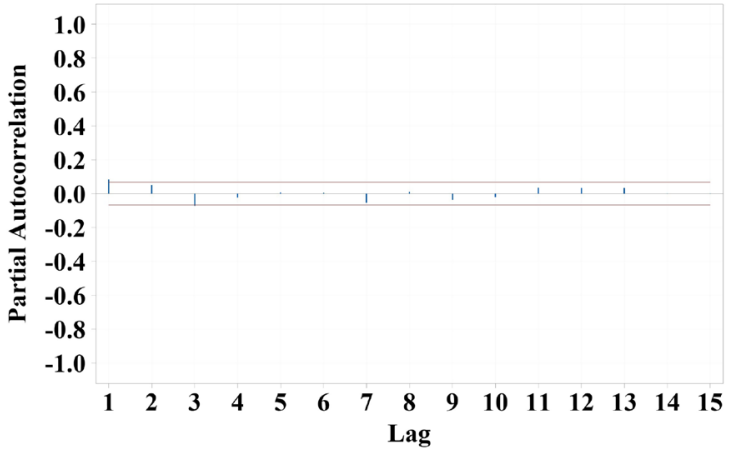

Autocorrelation Function for ALEXANDRIA (with $\mathbf{5 \%}$ significance limits for the autocorrelations)

Partial Autocorrelation Function for ALEXANDRIA (with $\mathbf{5 \%}$ significance limits for the partial autocorrelations)
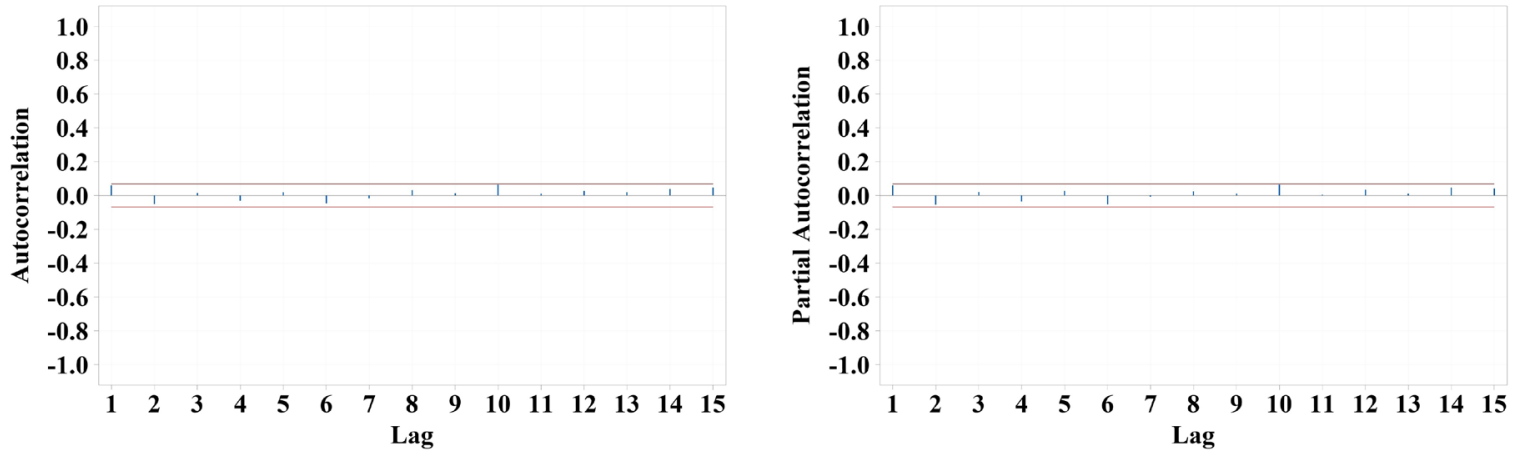

Figure 4. ACF and PACF plots new Orleans airport and Alexandria. 
Autocorrelation Function for LOGANSPORT AT DeSOTO (with $\mathbf{5 \%}$ significance limits for the autocorrelations)

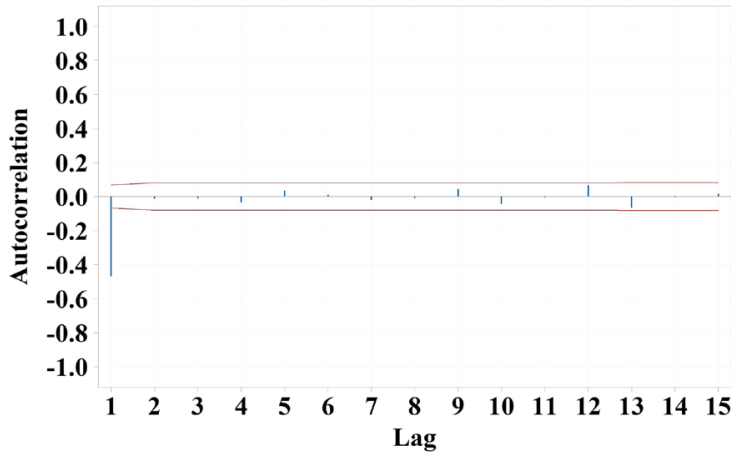

Autocorrelation Function for NEW ORLEANS AUDUBON (with $\mathbf{5 \%}$ significance limits for the autocorrelations)

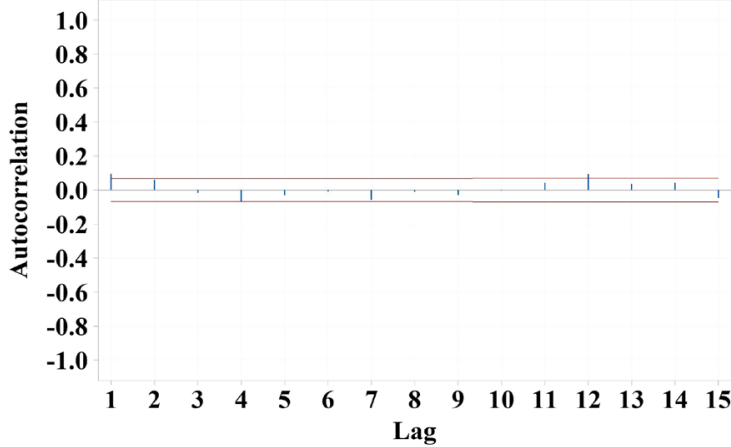

Partial Autocorrelation Function for LOGANSPORT AT DeSOTO (with $5 \%$ significance limits for the partial autocorrelations)

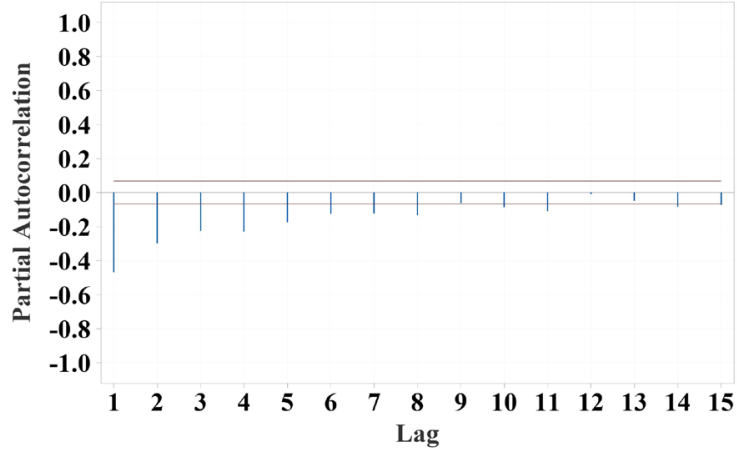

Partial Autocorrelation Function for NEW ORLEANS AUDUBON (with $5 \%$ significance limits for the partial autocorrelations)

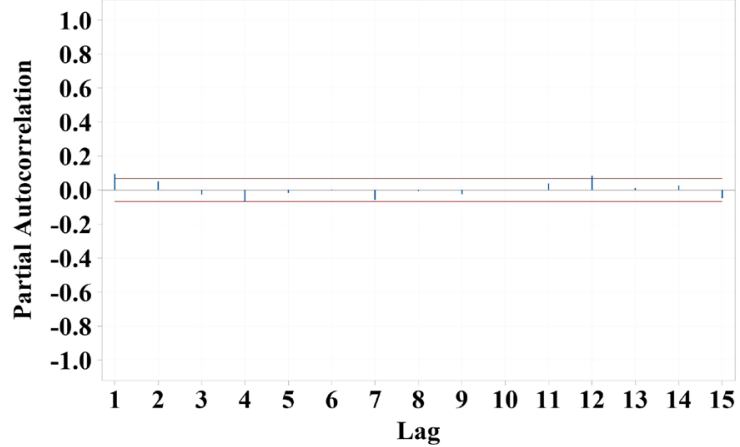

Figure 5. ACF and PACF plots for Logansport (Desoto) and new Orleans Audubon.

Autocorrelation Function for LAKE CHARLES REG. AIRPORT Partial Autocorrelation Function for LAKE CHARLES REG. AIRPORT (with $5 \%$ significance limits for the autocorrelations) (with $\mathbf{5 \%}$ significance limits for the partial autocorrelations)
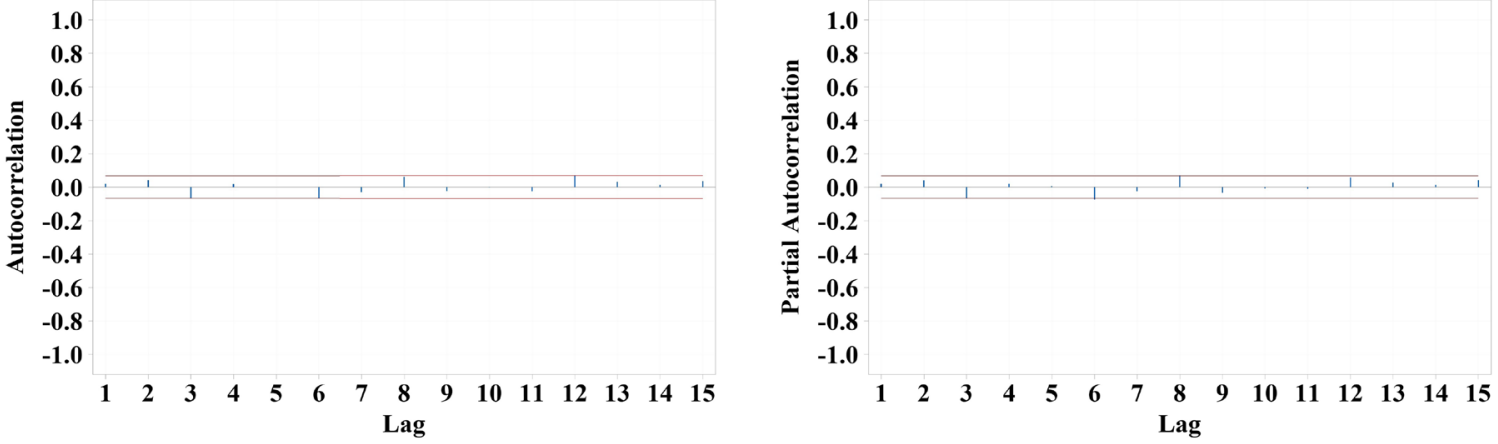

Autocorrelation Function for BATON ROUGE RYAN (with $\mathbf{5 \%}$ significance limits for the autocorrelations)

Partial Autocorrelation Function for BATON ROUGE RYAN (with 5\% significance limits for the partial autocorrelations)
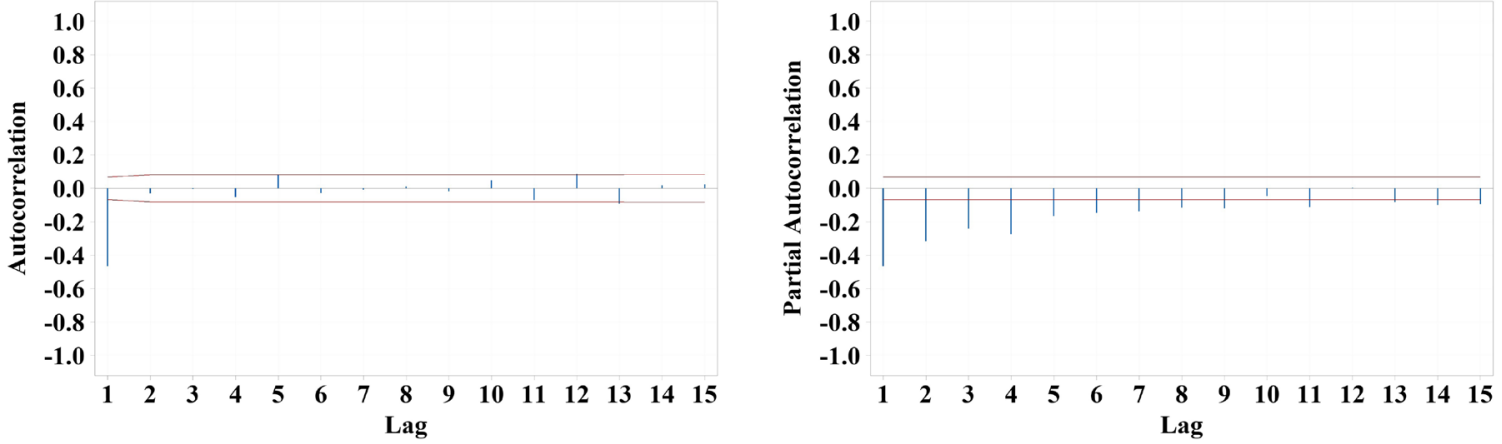

Figure 6. ACF and PACF plots for lake Charles regional airport and baton rouge. 
The best models out of the tentative models have been identified by the AIC and BIC from Table 4 for each station. The accuracy of the models is represented in Table 5. Both the RMSE and MAE have less values hence values forecasted would be nearer to or exact as their actual values. This indicates that the models developed are good fit for precipitation data from Louisiana and can be used to generate future precipitation values to help in decision making in the State by government and individuals.

\subsection{Forecasting}

Forecasted values were generated from each selected model. The values estimated are near compared to the original precipitation values and fall within the upper and lower limit intervals as depicted below in Tables 6(a)-(h).

In order to ascertain the accuracy of the forecasted values, the precipitation values of the year 2020 were used as a base for comparison. If the forecasted values are close to the actual values, and follow a similar trend, then the model is said to be performing better [27] [28] [29]. Tables 6(a)-(f) shows that the forecasted values follow the same pattern as the original values. This is a good indicator as established earlier that the model constructed is good model.

\section{Discussions}

New Orleans Airport and New Orleans Audubon observed the most precipitation whiles the least precipitation was recorded at Monroe Regional Airport. The two stations at New Orleans are both in the coastal zone. This can be a key contribution to the high precipitation at these stations. The time series plot shows that both New Orleans Airport and New Orleans Audubon recorded the highest precipitation in 1991 and since has been fluctuating between $40 \mathrm{~mm}$ and $80 \mathrm{~mm}$ per year. Abbeville, Monroe Regional Airport, and Alexandria also recorded their highest precipitation in 1991 after series of fluctuations in the precipitation values at these stations. Logansport and Lake Charles Airport recorded their peak values in 1997 and 2004 respectively. Precipitation at these two stations fluctuates between $76 \mathrm{~mm}$ and $26 \mathrm{~mm}$ per year. All these characteristics were all captured in the established models for each of the stations.

Table 5. Accuracy of the selected models.

\begin{tabular}{cccc}
\hline Area & Tentative Model & RMSE & MAE \\
\hline Baton Rouge & ARIMA $(0,1,1)(1,0,0)_{12}$ & 3.2827 & 2.4522 \\
Abbeville & ARMA $(0,0,1)(0,0,2)_{12}$ & 2.9694 & 1.9088 \\
Monroe Regional & ARMA $(0,0,1)(0,0,0)_{12}$ & 2.9284 & 2.2484 \\
New Orleans Airport, & ARMA $(1,0,0)(0,0,2)_{12}$ & 3.5019 & 2.6308 \\
Alexandria & ARMA $(1,0,1)(0,0,0)_{12}$ & 3.0557 & 2.3604 \\
Logansport & ARIMA $(0,1,2)(0,0,0)_{12}$ & 2.6199 & 1.8052 \\
New Orleans Audubon & ARMA $(1,0,0)(0,0,0)_{12}$ & 3.5435 & 2.6505 \\
Lake Charles Airport & ARMA $(2,0,2)(0,0,0)_{12}$ & 3.5435 & 2.6505 \\
\hline
\end{tabular}


Table 6. (a) Forecast for the year 2020; (b) Forecast for the year 2020; (c) Forecast for the year 2020; (d) Forecast for the year 2020; (e) Forecast for the year 2020; (f) Forecast for the year 2020; (g) Forecast for the year 2020; (h) Forecast for the year 2020.

(a)

\begin{tabular}{ccccc}
\hline \multicolumn{2}{c}{ Alexandria } & \multicolumn{2}{c}{$95 \%$ Limits } & \multirow{2}{*}{ Actual } \\
\cline { 1 - 2 } Period & Forecast & Lower & Upper & \\
\hline Jan 20 & 4.70 & -1.15 & 10.88 & 8.61 \\
Feb 20 & 4.92 & -1.17 & 10.86 & 5.40 \\
Mar 20 & 4.78 & -1.16 & 10.87 & 4.70 \\
Apr 20 & 4.87 & -1.17 & 10.86 & 6.67 \\
May 20 & 4.82 & -1.16 & 10.87 & 6.20 \\
Jun 20 & 4.85 & -1.16 & 10.86 & 5.36 \\
Jul 20 & 4.85 & -1.16 & 10.87 & 5.43 \\
Aug 20 & 4.84 & -1.16 & 10.86 & 8.35 \\
\hline
\end{tabular}

(b)

\begin{tabular}{ccccc}
\hline \multicolumn{2}{c}{ Abbeville } & \multicolumn{2}{c}{$95 \%$ Limits } & Actual \\
\hline Period & Forecast & Lower & Upper & \\
\hline Jan 20 & 5.59 & -0.32 & 11.51 & 6.88 \\
Feb 20 & 4.89 & -1.02 & 10.80 & 2.52 \\
Mar 20 & 4.68 & -1.23 & 10.60 & 5.08 \\
Apr 20 & 5.67 & -0.25 & 11.58 & 5.23 \\
May 20 & 5.35 & -0.57 & 11.26 & 5.27 \\
Jun 20 & 5.42 & -0.49 & 11.34 & 6.61 \\
Jul 20 & 6.34 & 0.42 & 12.25 & 10.27 \\
Aug 20 & 5.69 & -0.22 & 11.60 & 6.28 \\
\hline
\end{tabular}

(c)

\begin{tabular}{|c|c|c|c|c|}
\hline \multicolumn{2}{|c|}{ Baton Rouge } & \multicolumn{2}{|c|}{ 95\% Limits } & \multirow{2}{*}{ Actual } \\
\hline Period & Forecast & Lower & Upper & \\
\hline $\operatorname{Jan} 20$ & 5.49 & -0.90 & 11.88 & 5.18 \\
\hline Feb 20 & 5.47 & -0.92 & 11.86 & 6.22 \\
\hline Mar 20 & 5.44 & -0.96 & 11.83 & 2.2 \\
\hline Apr 20 & 5.63 & -0.76 & 12.02 & 7.23 \\
\hline May 20 & 5.63 & -0.77 & 12.02 & 4.9 \\
\hline Jun 20 & 5.58 & -0.82 & 11.97 & 8.74 \\
\hline Jul 20 & 5.57 & -0.83 & 11.97 & 8.91 \\
\hline Aug 20 & 5.58 & -0.81 & 11.98 & 4.61 \\
\hline
\end{tabular}


(d)

\begin{tabular}{ccccc}
\hline \multicolumn{2}{c}{ New Orleans Airport } & \multicolumn{2}{c}{$95 \%$ Limits } & \multirow{2}{*}{ Actual } \\
\cline { 1 - 3 } Period & Forecast & Lower & Upper & \\
\hline Jan 20 & 4.54 & -2.33 & 11.41 & 4.41 \\
Feb 20 & 4.83 & -2.07 & 11.72 & 3.94 \\
Mar 20 & 4.92 & -1.99 & 11.83 & 1.07 \\
Apr 20 & 5.16 & -1.75 & 12.07 & 5.42 \\
May 20 & 4.90 & -2.01 & 11.81 & 8.36 \\
Jun 20 & 5.18 & -1.73 & 12.09 & 10.16 \\
Jul 20 & 5.19 & -1.72 & 12.10 & 15.22 \\
Aug 20 & 5.38 & -1.53 & 12.29 & 6.28 \\
\hline
\end{tabular}

(e)

\begin{tabular}{ccccc}
\hline \multicolumn{2}{c}{ Monroe Regional } & \multicolumn{2}{c}{$95 \%$ Limits } & \multirow{2}{*}{ Actual } \\
\cline { 1 - 3 } Period & Forecast & Lower & Upper & \\
\hline Jan 20 & 4.35 & -1.42 & 10.11 & 10 \\
Feb 20 & 4.38 & -1.43 & 10.18 & 9.2 \\
Mar 20 & 4.38 & -1.43 & 10.18 & 5.7 \\
Apr 20 & 4.38 & -1.43 & 10.18 & 7.19 \\
May 20 & 4.38 & -1.43 & 10.18 & 4.2 \\
Jun 20 & 4.38 & -1.43 & 10.18 & 4.87 \\
Jul 20 & 4.38 & -1.43 & 10.18 & 4.78 \\
Aug 20 & 4.38 & -1.43 & 10.18 & 3.11 \\
\hline
\end{tabular}

(f)

\begin{tabular}{|c|c|c|c|c|}
\hline \multicolumn{2}{|c|}{ New Orleans Audubon } & \multicolumn{2}{|c|}{ 95\% Limits } & \multirow{2}{*}{ Actual } \\
\hline Period & Forecast & Lower & Upper & \\
\hline Jan 20 & 5.06 & -1.88 & 12.0 & 4.52 \\
\hline Feb 20 & 5.16 & -1.81 & 12.1 & 6.64 \\
\hline Mar 20 & 5.17 & -1.80 & 12.8 & 0.37 \\
\hline Apr 20 & 5.17 & -1.80 & 12.8 & 6.93 \\
\hline May 20 & 5.17 & -1.80 & 12.8 & 8.14 \\
\hline Jun 20 & 5.17 & -1.80 & 12.8 & 12.8 \\
\hline Jul 20 & 5.17 & -1.80 & 12.8 & 15.06 \\
\hline Aug 20 & 5.17 & -1.80 & 12.8 & 6.87 \\
\hline
\end{tabular}

(g)

\begin{tabular}{ccccc}
\hline \multicolumn{2}{c}{ Logansport } & \multicolumn{2}{c}{$95 \%$ Limits } & \multirow{2}{*}{ Actual } \\
\cline { 1 - 3 } Period & Forecast & Lower & Upper & \\
\hline Jan 20 & 4.47 & -1.31 & 10.24 & 6.06 \\
Feb 20 & 4.51 & -1.30 & 10.33 & 8.43 \\
\hline
\end{tabular}




\section{Continued}

\begin{tabular}{lllll}
\hline Mar 20 & 4.51 & -1.30 & 10.33 & 5.26 \\
Apr 20 & 4.51 & -1.30 & 10.33 & 10.26 \\
May 20 & 4.51 & -1.30 & 10.33 & 6.87 \\
Jun 20 & 4.51 & -1.30 & 10.33 & 2.00 \\
Jul 20 & 4.51 & -1.30 & 10.33 & 8.49 \\
Aug 20 & 4.51 & -1.30 & 10.33 & 10.01 \\
\hline
\end{tabular}

(h)

\begin{tabular}{ccccc}
\hline \multicolumn{2}{c}{ Lake Charles Airport } & \multicolumn{2}{c}{$95 \%$ Limits } & \multirow{2}{*}{ Actual } \\
\cline { 1 - 3 } Period & Forecast & Lower & Upper & \\
\hline Jan 20 & 4.32 & -1.72 & 10.36 & 6.28 \\
Feb 20 & 4.64 & -1.40 & 10.68 & 2.84 \\
Mar 20 & 5.19 & -0.86 & 11.24 & 1.67 \\
Apr 20 & 4.61 & -1.46 & 10.67 & 3.92 \\
May 20 & 4.68 & -1.39 & 10.74 & 6.63 \\
Jun 20 & 4.98 & -1.08 & 11.05 & 5.41 \\
Jul 20 & 4.72 & -1.35 & 10.79 & 4.95 \\
Aug 20 & 4.72 & -1.35 & 10.79 & 5.25 \\
\hline
\end{tabular}

Alexandria and Monroe Regional Airport observes the most precipitation in the first quarter (January-March) over the years. Logansport also records high precipitations values during the second quarter (April-June) of each year. These stations decline in precipitation from the first quarter to the third quarter (July-September) of the year and then increase during the fourth quarter (October-December) of the year.

Baton Rouge, Abbeville, New Orleans Airport, New Orleans Audubon and Lake Charles Airport all record their highest values in the third quarter of each year. These stations develop an increasing trend from first quarter to the third quarter of the year and then decline sharply when approaching the fourth quarter of the year. All the stations record their least precipitation values during the fourth quarter.

Generally, the accuracy test was judicious since the forecasted values obtained from the models are very close to the actual values and all fall within the confidence interval, therefore the models are said to be good fit for their respective datasets. The forecasted values for Logansport and Monroe Regional Airport seem to deviate a little from the out-of-sample raw data but fitted the in-sample data greatly. The model for Baton Rouge performed well as the forecasted values for in-sample and out-of-sample are all very close to the original data, hence it can be concluded that there is no significant difference between the forecasted values and the original data.

The models built for Abbeville, Alexandria and Lake Charles Airport were al- 
so found to be good fit from the accuracy values generated. This was further confirmed by the forecasted values generated by each of the models for their respective data. The forecasted values were very close to the actual data for each station.

New Orleans Airport and New Orleans Audubon models generated forecast values which were very close to both in-sample and out-of-sample data, but some few data points were out of the $95 \%$ confidence interval, this is due to the excess precipitation at the stations during the third quarter of the year. These two stations must be given great attention since they are found around the coastal zone, therefore predicting future precipitation values for these stations would help curb many disasters that is caused by excessive precipitation. Farmers can also benefit greatly from the model since most farming activities depend on precipitation.

\section{Conclusion}

As stated earlier, precipitation plays a key role in decision making in agriculture, hydrology, and even climate change. The study showed that in the long term, precipitation follows a linear and increasing trend in all stations except for New Orleans which had a decreasing trend. Again, the suitable models identified were Baton Rouge (ARIMA $\left.(0,1,1)(0,0,2)_{12}\right)$, Abbeville (ARMA $\left.(0,0,1)(0,0,2)_{12}\right)$, Monroe Regional (ARMA $\left.(0,0,1)(0,0,0)_{12}\right)$, New Orleans Airport (ARMA $(1,0,0)$ $\left.(0,0,2)_{12}\right)$, Alexandria (ARMA $\left.(1,0,1)(0,0,0)_{12}\right)$, Logansport (ARIMA $(0,1,2)$ $\left.(0,0,0)_{12}\right)$, New Orleans Audubon (ARMA $\left.(1,0,0)(0,0,0)_{12}\right)$, Lake Charles Airport (ARMA $\left.(2,0,2)(0,0,0)_{12}\right)$ and each model was found to be a good fit for modelling precipitation data from Louisiana State. It is recommended that government, researchers, and individuals take note of these models to make future plans to help increase production of agricultural commodities and prevent destructions caused by excessive precipitation.

\section{Acknowledgements}

This work was supported by the United States Department of Agriculture (USDA) National Institute of Food and Agriculture, McIntire Stennis Project NI21MSCFRXXXG003.

\section{Conflicts of Interest}

The authors declare no conflicts of interest regarding the publication of this paper.

\section{References}

[1] Harpold, A.A., Kaplan, M.L., Klos, P.Z., Link, T., McNamara, J.P., Rajagopal, S., Schumer, R. and Steele, C.M. (2017) Rain or Snow: Hydrologic Processes, Observations, Prediction, and Research Needs. Hydrology and Earth System Sciences, 21, 1-22. https://doi.org/10.5194/hess-21-1-2017

[2] Rosenberg, E.A., Keys, P.W., Booth, D.B., Hartley, D., Burkey, J., Steinemann, A.C. 
and Lettenmaier, D.P. (2010) Precipitation Extremes and the Impacts of Climate Change on Stormwater Infrastructure in Washington State. Climatic Change, 102, 319-349. https://doi.org/10.1007/s10584-010-9847-0

[3] Yu, P.-S., Yang, T.-C. and Wu, C.-K. (2002) Impact of Climate Change on Water Resources in Southern Taiwan. Journal of Hydrology, 260, 161-175.

https://doi.org/10.1016/S0022-1694(01)00614-X

[4] Tripathi, M.P., Panda, R.K., Raghuwanshi, N.S. and Singh, R. (2004) Hydrological Modelling of a Small Watershed Using Generated Rainfall in the Soil and Water Assessment Tool Model. Hydrological Processes, 18, 1811-1821. https://doi.org/10.1002/hyp.1448

[5] Marshall, J.S., Langille, R.C. and Palmer, W.M.K. (1947) Measurement of Rainfall by Radar. Journal of Meteorology, 4, 186-192. https://doi.org/10.1175/1520-0469(1947)004<0186:MORBR>2.0.CO;2

[6] Gaaloul, N., Eslamian, S. and Katlance, R. (2020) Impacts of Climate Change and Water Resources Management in the Southern Mediterranean Countries. Water Productivity Journal, 1, 51-72.

[7] Vörösmarty, C.J., Green, P., Salisbury, J. and Lammers, R.B. (2000) Global Water Resources: Vulnerability from Climate Change and Population Growth. Science, 289, 284-288. https://doi.org/10.1126/science.289.5477.284

[8] Celik, S. (2020) The Effects of Climate Change on Human Behaviors. In: Fahad, S., Hasanuzzaman, M., Alam, M., Ullah, H., Saeed, M., Ali Khan, I. and Adnan, M., Eds., Environment, Climate, Plant and Vegetation Growth, Springer, Berlin, Chapter 22, 577-589.

[9] Handmer, J., Honda, Y., Kundzewicz, Z.W., Arnell, N., Benito, G., Hatfield, J., Mohamed, I.F., Peduzzi, P., Wu, S., Sherstyukov, B., Takahashi, K., Yan, Z., Abdulla, A., Bouwer, L.M., Campbell, J., Hashizume, M., Hattermann, F.F., Heilmayr, R., Keating, A., Ladds, M., Mach, K.J., Mastrandrea, M.D., Mechler, R., Nobre, C., Sanghi, A., Screen, J., Smith, J., Velegrakis, A., Vergara, W., Waite, A.M., Westrich, J., Whittaker, J., Yunhe, Y. and Yamano, H. (2012) Changes in Impacts of Climate Extremes: Human Systems and Ecosystems. In: Managing the Risks of Extreme Events and Disasters to Advance Climate Change Adaptation, Special Report of the Intergovernmental Panel on Climate Change, Special Report of the IPCC, 231-290. https://doi.org/10.1017/CBO9781139177245.007

[10] Mooney, H., Larigauderie, A., Cesario, M., Elmquist, T., Hoegh-Guldberg, O., Lavorel, S., Mace, G.M., Palmer, M., Scholes, R. and Yahara, T. (2009) Biodiversity, Climate Change, and Ecosystem Services. Current Opinion in Environmental Sustainability, 1, 46-54. https://doi.org/10.1016/j.cosust.2009.07.006

[11] Parmesan, C. (2006) Ecological and Evolutionary Responses to Recent Climate Change. Annual Review of Ecology, Evolution, and Systematics, 37, 637-669. https://doi.org/10.1146/annurev.ecolsys.37.091305.110100

[12] Rogers, C.E. and McCarty, J.P. (2000) Climate Change and Ecosystems of the Mid-Atlantic Region. Climate Research, 14, 235-244.

https://doi.org/10.3354/cr014235

[13] Sheffield, J. and Wood, E.F. (2008) Global Trends and Variability in Soil Moisture and Drought Characteristics, 1950-2000, from Observation-Driven Simulations of the Terrestrial Hydrologic Cycle. Journal of Climate, 21, 432-458. https://doi.org/10.1175/2007JCLI1822.1

[14] Dore, M.H.I. (2005) Climate Change and Changes in Global Precipitation Patterns: 
What Do We Know? Environment International, 31, 1167-1181. https://doi.org/10.1016/j.envint.2005.03.004

[15] Gafforov, K.S., Bao, A., Rakhimov, S., Liu, T., Abdullaev, F., Jiang, L., Durdiev, K., Duulatov, E., Rakhimova, M. and Mukanov, Y. (2020) The Assessment of Climate Change on Rainfall-Runoff Erosivity in the Chirchik-Akhangaran Basin, Uzbekistan. Sustainability, 12, 3369. https://doi.org/10.3390/su12083369

[16] Faridzad, M., Yang, T., Hsu, K., Sorooshian, S. and Xiao, C. (2018) Rainfall Frequency Analysis for Ungauged Regions Using Remotely Sensed Precipitation Information. Journal of Hydrology, 563, 123-142. https://doi.org/10.1016/j.jhydrol.2018.05.071

[17] Li, H., Wang, D., Singh, V.P., Wang, Y., Wu, J., Wu, J., Liu, J., Zou, Y., He, R. and Zhang, J. (2019) Non-Stationary Frequency Analysis of Annual Extreme Rainfall Volume and Intensity Using Archimedean Copulas: A Case Study in Eastern China. Journal of Hydrology, 571, 114-131. https://doi.org/10.1016/j.jhydrol.2019.01.054

[18] Rahman, M.S. and Islam, A.R.M.T. (2019) Are Precipitation Concentration and Intensity Changing in Bangladesh Overtimes? Analysis of the Possible Causes of Changes in Precipitation Systems. Science of the Total Environment, 690, 370-387. https://doi.org/10.1016/j.scitotenv.2019.06.529

[19] Vivekanandan, N. (2020) Evaluation of Estimators of Probability Distributions for Frequency Analysis of Rainfall and River Flow Data. Evaluation, 4, 69-75.

[20] Gong, X. and Richman, M.B. (1995) On the Application of Cluster Analysis to Growing Season Precipitation Data in North America East of the Rockies. Journal of Climate, 8, 897-931. https://doi.org/10.1175/1520-0442(1995)008<0897:OTAOCA $>2.0 . C O ; 2$

[21] Salviano, M.F., Groppo, J.D. and Pellegrino, G.Q. (2016) Trends Analysis of Precipitation and Temperature Data in Brazil. Revista Brasileira de Meteorologia, 31, 64-73. https://doi.org/10.1590/0102-778620150003

[22] Tan, X., Gan, T.Y. and Shao, D. (2016) Wavelet Analysis of Precipitation Extremes over Canadian Ecoregions and Teleconnections to Large-Scale Climate Anomalies. Journal of Geophysical Research: Atmospheres, 121, 14469-14486. https://doi.org/10.1002/2016JD025533

[23] Naghavi, B. and Yu, F.X. (1993) Extreme Rainfall Frequency Analysis for Louisiana. Transportation Research Record, 1420, 78-83.

[24] Habib, E., Henschke, A. and Adler, R.F. (2009) Evaluation of TMPA Satellite-Based Research and Real-Time Rainfall Estimates during Six Tropical-Related Heavy Rainfall Events over Louisiana, USA. Atmospheric Research, 94, 373-388. https://doi.org/10.1016/j.atmosres.2009.06.015

[25] Donders, A.R.T., Van Der Heijden, G.J.M.G., Stijnen, T. and Moons, K.G.M. (2006) Review: A Gentle Introduction to Imputation of Missing Values. Journal of Clinical Epidemiology, 59, 1087-1091. https://doi.org/10.1016/j.jclinepi.2006.01.014

[26] Box, G.E.P. and Jenkins, G.M. (1968) Some Recent Advances in Forecasting and Control. Journal of the Royal Statistical Society: Series C (Applied Statistics), 17, 91-109. https://doi.org/10.2307/2985674

[27] Bailey, R.L., Halbedl, T.S., Schattauer, I., Achleitner, G. and Leonhardt, R. (2018) Validating GIC Models with Measurements in Austria: Evaluation of Accuracy and Sensitivity to Input Parameters. Space Weather, 16, 887-902. https://doi.org/10.1029/2018SW001842

[28] Hyndman, R.J. (2014) Measuring Forecast Accuracy. In: Business Forecasting. Prac- 
tical Problems and Solutions, John Wiley \& Sons, Hoboken, 177-183.

[29] Hyndman, R.J. and Athanasopoulos, G. (2021) Forecasting: Principles and Practice. 3rd Edition, Otexts Publishing. 